\title{
NnLAC17, a Gene Related to Lignin Synthesis, is Involved in Adventitious Root Formation in the Seedlings of Lotus (Nelumbo Nucifera Gaertn)
}

Cheng libao ( $\sim$ lbcheng@yzu.edu.cn )

Yangzhou University

\section{Zhao Chen}

Yangzhou University

Zhao minrong

Yangzhou University

Han yuyan

Yangzhou University

Li Shuyan

Yangzhou University

\section{Research Article}

Keywords: Lotus, ARs, lignin, NnLAC17, LC-MS/MS

Posted Date: September 7th, 2021

DOl: https://doi.org/10.21203/rs.3.rs-849586/v1

License: (9) This work is licensed under a Creative Commons Attribution 4.0 International License. Read Full License 


\section{Abstract}

\section{Barkground}

Adventitious roots (ARs), which are considered as an important member of root system, have an unmatched status in plant growth and metabolism due to the degeneration of primary roots in lotus. The regulation of $A R$ formation was previously revealed and multiple factors were recognized to be involved in this biological process.

\section{Results}

In the present study, we sought to assess the effect of sucrose on AR formation. Based on our results, lignin metabolism, which is regulated by the sucrose signal transduction pathway, is involved in AR development. The lignification degree of the AR primordium was weaker in plants treated with $20 \mathrm{~g} / \mathrm{L}$ sucrose than in control plants. However, based on the microstructural observation of the AR developmental process, $50 \mathrm{~g} / \mathrm{L}$ sucrose promoted the lignification process. Lignin content, including monomer and polymer lignin, was determined in the present study. Compared with control plants, the monomer (containing 30\%-45\% S type and 55\%-70\% G type) and polymer lignin contents were lower in plants treated with $20 \mathrm{~g} / \mathrm{L}$ sucrose and higher in plants treated with $50 \mathrm{~g} / \mathrm{L}$ sucrose. The precursors of monomer lignin were identified in four libraries of differential developmental stages in seedlings using LC-MS/MS technique. The contents of four metabolites, including p-coumaric acid, caffeate, sinapinal aldehyde and ferulic acid for monomer lignin synthsis were lower in the GL50 library than in the GL20 library. Further analysis revealed that the gene expression of these four metabolites had no novel difference in the GL50/GL20 libraries. However, NnLAC17, a gene involved in polymer lignin synthesis, had a higher expression in the GL50 library than in the GL20 library.

\section{Conclusions}

Therefore, NnLAC17 was cloned, and the overexpression of NnLAC17 was found to directly result in a decrease in AR number in transgenic Arabidopsis plants. These findings suggest that NnLAC17, which is relevant to lignin synthesis, is involved in AR formation in lotus seedlings.

\section{Background}

The lotus is an aquatic plant that contains multiple nutrients. The lotus is believed to be an important vegetable and is wildly cultivated in the Yangtze River and Yellow River basins owing to the suitable climate [1, 2]. In recent years, the lotus has become the largest cultivated area of aquatic vegetables. ARs are important member of root system that play an important role in water and nutrient uptake in plants, especially in lotus, which has underdeveloped primary roots. ARs are always located on the hypocotyl of seedlings in lotus, and approximately two weeks are required for ARs emergence [3]. There are three developmental stages in the entire period of ARs formation [4, 5]: the first stage is the induced period, where the normal cell is divided and developed into meristematic cells; the second stage is the 
development stage, where the root primordium is formed from meristematic cells [6]; and the third stage, where the root primordium emerges from the epidermis of the stem or leaf [7, 8]. All biological processes of AR formation are strictly controlled by internal and external factors, such as light, plant hormones, damage, and sucrose.

The signaling transduction pathway of plant hormone is found to be involved in various metabolic processes of plant growth. In the past years, IAA has been reported to play an important role in root formation at the introduced, developmental, and emergence stages $[9,10]$. Any factors that affect the synthesis, degradation, and transport of IAA can affect the development of AR. The formation of AR, an irreplaceable organ for water and nutrition uptake, is strictly controlled by ethylene [11]. Thus, the role of ethylene in AR formation is mainly carried out at the induction stage $[12,13,14]$. IAA and ethylene could also cooperatively regulate AR development. The metabolism and sensitivity of auxin are affected by ethylene. However, the role of ethylene is also regulated by IAA $[15,16,17]$. Sugar is involved in root development [18]. In fact, the role of sucrose in the regulation of root formation has been revealed to be similar to that of some types of plant hormone. Further, sucrose can promote the formation of root primordium and late development $[10,19]$. In lotus, there is an interaction between sucrose and IAA during AR formation and the exogenous application of sucrose can affect IAA content. Exogenous IAA also changes endogenous sucrose content during AR formation [20]. Lignin is an important component of cells during plant growth and metabolism [21]. Normally, lignin, which is a polyphenolic polymer, contains three types of monomers, namely the S-type, H-type, and G-type [22].

According to recently reported data, a close relationship exists between lignin metabolism and AR formation. Cho et al. [23] reveals that IBA treatment promotes root primordial development but suppressed lignin synthesis. Peroxidase genes are responsible for lignin synthesis [24]. In fact, these peroxidase genes expression is found to be upregulated after IBA treatment [25]. Moreover, two different types of Ebenus cretica (rooting and non-rooting genotypes) are found to have different lignin and peroxidase activities [26]. In sweet potato, the formation of storage root is reduced and vascular lignification is promoted after the exogenous application of gibberellin [27]. A high expression of genes related to lignin synthesis occurs in wild species (not from storage roots) relative to cultivated species [28]. In mung bean seedlings, the genes responsible for lignin biosynthesis are downregulated after IBA treatment, which significantly promotes AR formation [29]. The development of rice roots is previously found to be inhibited while lignin deposition is increased in cell walls under conditions of stress [30].

Sucrose is an important signal molecular, which is involved in various biological process in plant. In the previous study, we found that sucrose metabolism was involved in AR development, and the expression of the gene, $N n L A C 17$ (which was related to lignin metabolism), was altered after plants were treated with 20 and $50 \mathrm{~g} / \mathrm{L}$ sucrose. Fifty $\mathrm{g} / \mathrm{L}$ sucrose (which inhibited AR formation in lotus seedlings) caused a greater transcription level of $N n L A C 17$ than $20 \mathrm{~g} / \mathrm{L}$ sucrose (which promoted AR formation in lotus seedlings) [20]. Therefore, NnLAC17 might play a critical role in lignin synthesis and regulate AR formation. In this study, the lignin content, a lignin metabolite, gene expression at the genomic level, and 
the biological function of $N n L A C 17$ during AR formation were assessed to explore the AR mechanism regulated by sucrose in lotus seedlings.

\section{Methods}

\section{Plant growth}

The lotus seed species, Taikong36, was selected for all experiments in this study. The seeds used in this study were derived from the open field of Yangzhou University, and necessary permission was obtained to collect these samples. In spring (usually in April), the lotus was planted in the field for germination with moist soil. After the petiole broke through the soil surface, the water depth was maintained at 5-10 cm; a deeper water $(20-40 \mathrm{~cm})$ was required for the development of the plant and temperature was maintained between 20 and $30^{\circ} \mathrm{C}$ during the entire growth season. The application of fertilizer and pest control was carried out in the same manner employed in the conventional management of the field. The seeds were harvested in November and placed in a container at normal temperature.

\section{The role of sucrose in AR formation}

The seed coat of lotus was punched to enable the uptake of available water (for approximately three days) and placed at $26^{\circ} \mathrm{C}$ for approximately three days under dark conditions. Fifty germinated seedlings from each treatment were selected and placed into $0 \mathrm{~g} / \mathrm{L}, 20 \mathrm{~g} / \mathrm{L}$, and $50 \mathrm{~g} / \mathrm{L}$ sucrose solutions for two days. The germination rates and numbers were counted on days $0,2,4$, and 6 after transfer into water for $2 \mathrm{~d}$. All statistical data were expressed as the mean \pm SE of three repetitions of experiments. The SPSS software ver. 14.0 (SPSS Inc., Chicago, IL, USA) was used for statistical analyses.

\section{Observation of the paraffin sections}

The lotus seed coat was broken and immersed in water for approximately three days for germination at $26^{\circ} \mathrm{C}$ in the dark. The germinated seeds were selected for treatment with various concentrations of sucrose $(0,20$, and $50 \mathrm{mg} / \mathrm{L})$ for two days. The seedling hypocotyls of plants subjected to the above treatments were selected from four time points $(0,2,4$, and $6 \mathrm{~d})$ after treatment. The selected samples were cut into small pieces of $2.5 \mathrm{~mm} \times 2.5 \mathrm{~mm} \times 2 \mathrm{~mm}$ (length, width and height), and then placed in a container filled with FAA fixing fluid (solution amount was 20 -fold that of samples).

The container with fixed samples was produced in a vacuum state using a syringe for $5 \mathrm{~s}$. The lid of the container was opened for gas exchange after five min. This process was repeated in triplicate. The container was transferred to a clean bench at normal temperature for $24 \mathrm{~h}$. Thereafter, $50 \%, 70 \%, 85 \%$, $95 \%$, and $100 \%$ ethanol were applied to dehydrate the samples for approximately $25-30 \mathrm{~min}$. After dehydration with ethanol, the samples were treated with a mixed solution (one-half volume of ethanol and one-half volume of xylene and pure xylene) for approximately 25-30 min. Paraffin debris was 
prepared and thawed on an electric stove and then poured into the container with the samples for $24 \mathrm{~h}$.

The tissues embedded in paraffin were cut into small blocks, and $10 \mu \mathrm{m}$ of wax tape was prepared using a slicer. The wax tapes were placed on a glass slide, and then respectively transferred into pure xylene, mixed solution (one-half volume of pure xylene and one-half volume of absolute ethanol), and absolute ethanol for $10 \mathrm{~min}$. The slide was dried at room temperature, and $2-3$ drops of $0.75 \%$ crystal violet solution were placed on the samples for $5 \mathrm{~min}$. The samples were washed with distilled water and then observed using an optical microscope.

\section{Determination of monomer lignin and polymer lignin contents}

The seed coat was broken for water absorption. The broken seeds were immersed in water $\left(26^{\circ} \mathrm{C}\right.$ in the dark) for three days. After germination, two concentrations ( $20 \mathrm{mg} / \mathrm{L}$ and $50 \mathrm{mg} / \mathrm{L}$ ) of sucrose were applied as treatments to the plants for two days, with water as a control. The hypocotyls of seedlings were used as materials to determine the monomer lignin and polymer lignin contents. Ten milligrams of dried sample was added to a mixture (2.5\% boron trifluoride, $10 \%$ ethanethiol, $87.5 \%$ dioxane) for $4 \mathrm{~h}$ in a metal bath followed by $300 \mu \mathrm{L}$ of $0.4 \mathrm{~m}$ sodium bicarbonate. The mixture was vibrated, and $2 \mathrm{ml}$ water and $0.3 \mathrm{ml}$ ethyl acetate were added. The mixture was centrifuged at $14000 \mathrm{rpm}$ for $10 \mathrm{~min}$ at normal temperature, and the supernatant was retrieved. The supernatant was dried with nitrogen, and $150 \mu \mathrm{L}$ pyridine (including an internal standard) and $50 \mu \mathrm{L}$ trimethylsilane were allowed to react at $60^{\circ} \mathrm{C}$ for $1 \mathrm{~h}$. The mixture was centrifuged at $10000 \mathrm{rpm}$ for $10 \mathrm{~min}$ at normal temperature, and the supernatant was retrieved for lignin identification. The lignin content was determined using a GC-MS instrument (7820A5977B) from Agilent Technologies Inc. (CA, USA). The conditions for chromatography (mass spectrometry) and quantitative analysis lignin were based on a previous protocol [31]. Three biological replicates was carried out in this experiment. In addition, the roots of five-to six-leaf stage seedlings of transgenic Arabidopsis plants and none of the transgenic plants were collected for polymer lignin identification. The material treatment and identification method was the same as that mentioned above.

\section{Metabolite analysis of lignin during AR formation}

Lotus seedlings were treated with sucrose $(20 \mathrm{~g} / \mathrm{L}$ and $50 \mathrm{~g} / \mathrm{L})$ for two days, the detail progress were the same as above mentioned. The hypocotyls of control plants and plants treated with $20 \mathrm{~g} / \mathrm{L}$ and $50 \mathrm{~g} / \mathrm{L}$ were selected for metabolites analysis. All freeze-dried hypocotyls were crushed using a mixer mill (MM 400, Retsch) with a zirconia bead for $1.5 \mathrm{~min}$ at $30 \mathrm{~Hz}$. Powder powder (100 mg) was weighed and extracted overnight at $4{ }^{\circ} \mathrm{C}$ with $1.2 \mathrm{ml} 70 \%$ aqueous methanol. Following centrifugation at $10,000 \mathrm{~g}$ for $10 \mathrm{~min}$ at normal temperature, the extracts were absorbed (CNWBOND Carbon-GCB SPE Cartridge, $250 \mathrm{mg}, 3 \mathrm{ml}$; ANPEL, Shanghai, China, www.anpel.com.cn/cnw) and filtered (SCAA-104, 0.22 $\mu \mathrm{m}$ pore size; ANPEL, Shanghai, China, http://www.anpel.com.cn/) before UPLC-MS/MS analysis. 


\section{UPLC conditions}

The sample extracts were analyzed using a UPLC-ESI-MS/MS system (UPLC, Shim-pack UFLC SHIMADZUCBM 30A system, www. shimadzu. com.cn/; MS, Applied Biosystems 6500QTRAP, www.appliedbiosystems.com.cn). The analytical conditions were as follows: column, Waters ACQUITYUPLCHSST3C18 $(1.8 \mu \mathrm{m}, 2.1 \mathrm{~mm} * 100 \mathrm{~mm})$; and mobile phase, solvent A-pure water with $0.04 \%$ acetic acid and solvent B- acetonitrile with $0.04 \%$ acetic acid. Sample measurements were performed with an Agilent program that employed the starting conditions of $95 \%$ A and $5 \%$ B. Within 10 min, a linear gradient to $5 \% A$ and $95 \%$ B was employed, and a composition of $5 \% A$ and $95 \%$ B was maintained for 1 min. Subsequently, a composition of $95 \%$ A and $5.0 \%$ B was employed for 0.10 min and retained for $2.9 \mathrm{~min}$. The column oven temperature was set to $40^{\circ} \mathrm{C}$, and the injection volume was $2 \mu \mathrm{L}$. The effluent was alternatively connected to an ESI-triple quadrupole-linear ion trap (QTRAP)-MS.

\section{ESI-QTRAP-MS/MS}

LIT and triple quadrupole (QQQ) scans were acquired on a triple quadrupole-linear ion trap mass spectrometer (Q TRAP), API 6500 Q TRAP UPLC/MS/MS System, equipped with an ESI Turbo Ion Spray interface, operating in positive and negative ion mode and controlled by Analyst 1.6.3 software (AB Sciex). The ESI source parameters were as follows: ion source, turbo spray; source temperature, $550{ }^{\circ} \mathrm{C}$; ion spray voltage (IS), $5500 \mathrm{~V}$ (positive ion mode)/-4500 V (negative ion mode); ion source gas I (GSI), gas II (GSII), and curtain gas (CUR) 50, 60, and 30.0 psi, respectively; and collision gas (CAD), high. Instrument tuning and mass calibration were performed with 10 and $100 \mu \mathrm{mol} / \mathrm{L}$ polypropylene glycol solutions in the QQQ and LIT modes, respectively. QQQ scans were acquired as MRM experiments with a collision gas (nitrogen) set at 5 psi. DP and CE for individual MRM transitions were performed with further optimization of DP and CE. A specific set of MRM transitions was monitored for each period, according to the metabolites eluted within this period.

\section{RNA-seq analysis of the differentially expressed genes}

For the analysis of differentially expressed genes, all genes related to monomer and polymer lignin synthesis were selected and their expression profiles were monitored after treatment with sucrose during ARs formation. The lotus seed coat was broken before germination and placed in $5 \mathrm{~cm}$ water at $28-30{ }^{\circ} \mathrm{C}$ for germination. After germination, the seedlings were treated with sucrose $(20 \mathrm{mg} / \mathrm{L}$ and $50 \mathrm{mg} / \mathrm{L})$ and IAA $(10 \mu \mathrm{M}$ and $50 \mu \mathrm{M})$ for two days, and then placed in water for continued growth. RNAs were then extracted, and eight libraries were constructed for gene expression analysis (low concentrations of sucrose and IAA were demonstrated to promote AR formation while high concentration inhibited AR development in lotus seedlings). In the previous study, four libraries treated with different concentration of IAA (CK library: germinating seeds without treatment; A library: initial AR stages: 2 days of seedlings with $10 \mu \mathrm{M}$ IAA treatment; $B$ library: 2 days of seedlings without IAA treatment; $C$ library: 2 days of 
seedlings with $50 \mu \mathrm{M}$ IAA treatment) and sucrose (C0 library: the samples were collected at day 0; CK1, GL20 and GL50 libraries: the samples were collected at day 1) were constructed, and the data has been published by Cheng et al. [32] and Cheng et al. [20] respectively. Gene expression related to the synthesis of lignin including monomer and polymer lignin was selected from above libraries for further analysis.

\section{Cloning and sequence analysis of NnLAC17}

The sequence of $N n L A C 17$ was derived from the NCBI database according to the gene expression profile under sucrose treatment. Lotus RNA was extracted from the hypocotyls of three old seedlings using a plant RNA extract mix (Tiangen, Beijing, China). DNase was applied to eliminate residual DNA before cDNA synthesis, which was performed according to the protocol of the mix kit (Promega, USA). A total of $20 \mu \mathrm{L}$ of PCR reaction mixture, which included $2.5 \mu \mathrm{L}$ dNTP, $2 \mu \mathrm{L}$ forward and reverse primers, $2.5 \mu \mathrm{L}$ $\mathrm{MgCl}_{2}, 0.5 \mu \mathrm{L}$ Taq polymerase, $2 \mu \mathrm{L}$ cDNA fragments, and $9.5 \mu \mathrm{L} \mathrm{dH} \mathrm{H}_{2} \mathrm{O}$, was used. The PCR program included 35 cycles: $94^{\circ} \mathrm{C}$ for $1 \mathrm{~min}, 94^{\circ} \mathrm{C}$ for $1 \mathrm{~min}, 60^{\circ} \mathrm{C}$ for $1 \mathrm{~min}, 72{ }^{\circ} \mathrm{C}$ for $1 \mathrm{~min}$, and $72{ }^{\circ} \mathrm{C}$ for $10 \mathrm{~min}$. Forward primer: 5-ATGGGTTCCTTTGTTCTTCC-3; Reverse primer: 5-AGGCGGTAGTTTCTGATTTG-3. The plasma of DNA plasid was sent to Sangon Biotechnology Co., Ltd (Shanghai, China) for sequencing. For sequence analysis, five LACs including lotus, vitis riparia, vitis vinifera, spatholobus suberectus, and trema orientale were used for alignment anaysis by DNAman software. In addition, thirty-four LACs from different plants were selected, and MEGA-X software was used for phyogentic tree construction.

\section{Expression analysis of NnLAC17 in lotus}

The seed of the lotus was placed in a glass container with a water depth of $5 \mathrm{~cm}$ to allow germination at $28-30{ }^{\circ} \mathrm{C}$. The germinated seeds were treated with sucrose $(20 \mathrm{mg} / \mathrm{L}$ and $50 \mathrm{mg} / \mathrm{L})$ and IAA $(10 \mu \mathrm{M}$ and $150 \mu \mathrm{M})$ for $2 \mathrm{~d}$ and transferred into water to allow growth. The expression profile of $N n L A C 17$ was determined using qRT-PCR. The treatment of lotus seeds and the germination conditions were the same as those mentioned above. A total of 150 two-leaf seedlings which were divided into three groups, were treated with various concentrations of sucrose $(20 \mathrm{~g} / \mathrm{L}$ and $50 \mathrm{~g} / \mathrm{L})$ and IAA $(10 \mu \mathrm{M}$ and $150 \mu \mathrm{M})$ for 3 days respectively, and then transferred to water for continued growth. The hypocotyls of seedlings at $4 \mathrm{~d}$ after treatment were selected for transcription-level analysis. For the expression of NnLAC17 in different organs, the leaf, stem, and hypocotyls of seedlings at $6 \mathrm{~d}$ (cultivation in water) were selected to monitor expression changes. Total plant RNA was derived from these samples, and DNase was used to eliminate residual DNA. The primer was designed based on the $N n L A C 17$ sequence using the primer 5.0 software. Forward primer was 5-GGGTTCCTTTGTTCTTCCA-3, and reverse primer was: 5GCCAGTGCAAGGTGATATT-3. NnActin was used as the internal standard. The NnActin forward primer was 5'-ACGCGTATGAAGTCAGTTGT-3' and reverse primer, 5'-TTTATGGGGATCAGCTGGT-3'. A $25 \mu \mathrm{L}$ reaction mixture was prepared, which contained $12.5 \mu \mathrm{L}$ SYBR Premix Ex Taq II (Tli RNaseH Plus) (2x), 1 $\mu \mathrm{L}$ of each of the forward and reverse primers, $2 \mu \mathrm{L} c D N A$, and $8.5 \mu \mathrm{L} \mathrm{dH_{2 }} \mathrm{O}$. The PCR program consisted of $30 \mathrm{~s}$ at $94^{\circ} \mathrm{C}$, followed by 40 cycles of $95^{\circ} \mathrm{C}$ for $5 \mathrm{~s}$ and $60 \mathrm{~s}$ at $60^{\circ} \mathrm{C}$. Three biological replicates was 
carried out in this experiment. For data analysis, the $2^{-\triangle \triangle C t}$ method was used to identify NnLAC17 expression. The $\triangle \mathrm{Ct}$ value was obtained according to the $\mathrm{Ct}$ (target) and $\mathrm{Ct}$ (actin) values in treated plants $(\triangle \mathrm{Ct}$ (target)) and control $(\triangle \mathrm{Ct}$ (normal), and the $\triangle \triangle \mathrm{Ct}$ value was calculated according to the data of $\triangle \mathrm{Ct}$ (target) and $\triangle \mathrm{Ct}$ (normal). Based on the $\triangle \Delta \mathrm{Ct}$ value, the $2^{-} \Delta \triangle \mathrm{Ct}$ value was determined.

\section{Vector construction}

NnLAC17 was cloned and inserted into a clone vector (pGEM-T). pGEM-T was transformed into Escherichia coli to expand reproduction. After identification, positive clones were cultured in LB culture medium. The plasmid was extracted from bacterial fluid and digested with $\mathrm{BamHl}$ and $\mathrm{Kpn} /$ enzymes. Thereafter, the digestion product (sequence of $N n L A C 17$ ) was inserted into the plant transformation vector with a CaMV 35S promoter. The pSN1301:: NnLAC17 plasmid was inserted into the Agrobacterium tumefaciens strain, GV3101. The floral dip method [33] was employed to transform NnLAC17 into the wild-type Arabidopsis plant. The transformed Arabidopsis was cultured in the greenhouse, and seeds were harvested after approximately three months of growth. Sterilized seeds of the T0 generation were tiled on MS medium containing $20 \mu \mathrm{g} \cdot \mathrm{g}^{-1}$ hygromycin B to select 'positive' plants. The temperature of the chamber was $22^{\circ} \mathrm{C}$ with $12 \mathrm{~h}$ light and 12/dark light cycle. In addition, RT-PCR method was applied for further identification, and the primers was: Forward primer was 5-GGGTTCCTTTGTTCTTCCA-3, and reverse primer was: 5-GCCAGTGCAAGGTGATATT-3. Reaction mixture and program process were the same as gene expression. Base on the information of data, more than five lines of positive plants were selected for further study.

\section{Identification of NnLAC17 function in Arabidopsis plants}

The seeds of transgene (T2 generation) and wild-type plants were cultured in pots, and six-leaf-old transgenic seedlings and wild-type plants were selected for functional analysis. The development of all emerged roots including root length and number were determined. For root number analysis, all the root including ARs, primary root and lateral root were together counted (the hypocotyl of Arabidopsis was too short, so it was difficult to clearly distinguish ARs and primary root. Therefore, all the roots were identified together). For statistical analysis, all data are presented as the mean \pm SE of triplicate independent treatments with approximately 10 seedlings per experiment, and about thirty seedlings was used for three biological replicates. The SPSS software ver. 14.0 (SPSS Inc., Chicago, IL, USA) was for data analysis.

\section{Results}

\section{Effect of sucrose on AR formation}

The lotus seedlings were treated with different concentrations $(0,20 \mathrm{~g} / \mathrm{L}$, and $50 \mathrm{~g} / \mathrm{L})$ of sucrose to determine the effect of sucrose on AR development. The AR of seedlings treated with $20 \mathrm{~g} / \mathrm{L}$ sucrose 
broke through the hypocotyl within $2 \mathrm{~d}$. Further, the number of ARs in plants treated with $20 \mathrm{~g} / \mathrm{L}$ sucrose was greater than that of control plants after transferal to water. Such findings indicate that $20 \mathrm{~g} / \mathrm{L}$ sucrose significantly promoted the formation of ARs. The developmental process of ARs was markedly delayed in seedlings treated with $50 \mathrm{~g} / \mathrm{L}$ sucrose. In fact, the number of ARs was lower in plants treated with $50 \mathrm{~g} / \mathrm{L}$ sucrose than in control plants. Further analysis revealed that the seedlings treated with 20 $\mathrm{g} / \mathrm{L}$ sucrose had higher rates of AR formation than those treated with $50 \mathrm{~g} / \mathrm{L}$ sucrose. The rate of AR formation was only $50 \%$ at $6 \mathrm{~d}$ of growth in seedlings treated with $50 \mathrm{~g} / \mathrm{L}$ sucrose. In contrast, the rate of AR formation was $100 \%$ at $5 \mathrm{~d}$ in the seedlings treated with $20 \mathrm{~g} / \mathrm{L}$ sucrose (Fig. 1). In summary, we concluded that low concentrations of sucrose accelerated AR formation while high concentrations inhibited this process.

\section{Observation of the Paraffin sections}

The microstructure of hypocotyls was analyzed for AR development following treatment with $20 \mathrm{mg} / \mathrm{L}$ and $50 \mathrm{mg} / \mathrm{L}$ sucrose. The primordial of ARs were formed around the stomata in the hypocotyl. The induction and development of AR took approximately $2 \mathrm{~d}$ after treatment with $20 \mathrm{~g} / \mathrm{L}$ sucrose; however, a longer time was taken following treatment with $50 \mathrm{~g} / \mathrm{L}$ sucrose. In the last stage (expressed stage) of AR development, a greater number of ARs broke through the epidermis of hypocotyl following treatment with $20 \mathrm{mg} / \mathrm{L}$ sucrose than that at CKO and after treatment with $50 \mathrm{~g} / \mathrm{L}$ sucrose. Crystal violet staining was used to monitor the acclimation of lignin. Different degrees of staining were observed after treatment at $\mathrm{CKO}$ and after treatment with $20 \mathrm{~g} / \mathrm{L}$ and $50 \mathrm{~g} / \mathrm{L}$ sucrose during AR development. A more intense crystal violet staining was observed after treatment with $50 \mathrm{~g} / \mathrm{L}$ sucrose than at CKO and after treatment with 20 $\mathrm{g} / \mathrm{L}$ sucrose, indicating that the accumulation of lignin was higher following treatment with $50 \mathrm{~g} / \mathrm{L}$ sucrose than at CK and with $20 \mathrm{~g} / \mathrm{L}$ sucrose. Further, the lowest content of lignin was observed within $6 \mathrm{~d}$ of treatment with $20 \mathrm{~g} / \mathrm{L}$ sucrose (Fig. 2).

\section{Determination of monomer lignin and polymer lignin contents}

The seedlings were treated with $20 \mathrm{mg} / \mathrm{L}$ and $50 \mathrm{mg} / \mathrm{L}$ sucrose for three days, and the contents of monomer lignin and polymer lignin were determined at two stages (CK: $0 \mathrm{~d}$ of treatment; CK1, three days after treatment $(20 \mathrm{~g} / \mathrm{L}$ and $50 \mathrm{~g} / \mathrm{L})$ ). The lotus monomer lignin was found to be composed of two types of lignin ( $\mathrm{G}$ and $\mathrm{S}$ types); thus, it did not contain the $\mathrm{H}$ type. Of the two lignin types, the content of the Gtype lignin was greater than that of the S-type lignin. The lignin content of the $G$ and $S$ types was significantly higher at CK1 than CKO. At the same time, seedlings treated with $50 \mathrm{~g} / \mathrm{L}$ sucrose had higher lignin content than at CKO, while a remarkable decrease was observed after treatment with $20 \mathrm{~g} / \mathrm{L}$ sucrose (Fig. 3a). Further analysis revealed that more than $60 \%$ lignin was of the G-type lignin, and less than $40 \%$ lignin was of the S-type lignin at CKO and CK1 $(20 \mathrm{~g} / \mathrm{L}$ and $50 \mathrm{~g} / \mathrm{L}$ sucrose treatment) (Fig. 3b). The content of polymer lignin was also determined following the above treatments. The content of polymer lignin was found to increase at CK1 with $50 \mathrm{~g} / \mathrm{L}$ sucrose and CKO. Further, more content was found at CK1 and $50 \mathrm{~g} / \mathrm{L}$ sucrose than at CKO. However, total lignin was significantly decreased after treatment with $20 \mathrm{~g} / \mathrm{L}$ sucrose (Fig. $3 \mathrm{c}$ ). 


\section{The change in metabolites related to lignin biosynthesis owing to sucrose treatment}

Four libraries, namely CK0, CK1, GL20, and GL50, were constructed to monitor the change in 14 metabolites (p-coumaric acid, p-coumaraldehyde, sinapic acid, sinapyl alcohol, p-coumaryl alcohol, caffeyl alcohol, caffeyl aldehyde, sinapinaldehyde, L-phenylalanine, coniferyl alcohol, caffeate, ferulic acid, 4-hydroxy-3-methoxycinnamaldehyde, and cinnamic acid), which was involved in synthesis of monomer lignin in lotus seedlings treated with different concentrations of sucrose. Seven metabolites (sinapinaldehyde and 4-hydroxy-3-methoxycinnamaldehyde was involved in S-lignin synthesis; coniferyl alcohol, caffeate and ferulic acid were involved in G-lignin and S-lignin synthesis; L-phenylalanine and cinnamic acid were primary product for $\mathrm{H}$ lignin, G-lignin and S-lignin synthsins), six (sinapinaldehyde and4-hydroxy-3-methoxycinnamaldehyde Were involved in S-lignin synthesis; coniferyl alcohol, ferulic acid and, and cinnamic acid were involved in G-lignin and S-lignin synthesis; L-phenylalanine was primary product for $\mathrm{P}$ lignin, G-lignin and S-lignin synthsins), and six metabolites (sinapinaldehyde and 4-hydroxy3-methoxycinnamaldehyde were involved in S-lignin synthesis; coniferyl alcohol, ferulic acid and cinnamic acid were involved in $\mathrm{G}$ lignin and S-lignin synthesis; L-phenylalanine was primary product for $\mathrm{P}$ lignin, G-lignin and S-lignin synthsins) were found to increase, and only one metabolite (p-coumaric acid was involved in H-lignin synthesis) decreased in the CK1/CKO libraries, GL20/CK0, and GL50/CKO libraries, respectively. Based on the data obtained from these libraries, we further analyzed the altered metabolites in the GL50/GL20 libraries. The expression of four important metabolites, namely p-coumaric acid, caffeate, sinapinal aldehyde, and ferulic acid, were found to decrease (Table 1).

Table 1

Analysis of the metabolism of monomer lignin in lotus seedlings treated with $20 \mathrm{~g} / \mathrm{L}$ and $50 \mathrm{~g} / \mathrm{L}$ sucrose. 


\begin{tabular}{|c|c|c|c|}
\hline Compounds & Pvalue & Fold Change & Type \\
\hline \multicolumn{4}{|l|}{ CK1/CKO libraries } \\
\hline p-Coumaric acid & 0.0112 & 0.2743 & Down-regulated \\
\hline p-Coumaraldehyde & NA & NA & \\
\hline Sinapic acid & NA & NA & \\
\hline Sinapyl alcohol & NA & NA & \\
\hline p-Coumaryl alcohol & NA & NA & \\
\hline Caffeyl alcohol & NA & NA & \\
\hline Caffeyl aldehyde & NA & NA & \\
\hline Sinapinaldehyde & 0.0015 & 3.4747 & Up-regulated \\
\hline L-Phenylalanine & 0.00525 & 1.8344 & Up-regulated \\
\hline Coniferyl alcohol & 0.0225 & 23.0678 & Up-regulated \\
\hline Caffeate & 0.0305 & 1.4309 & Up-regulated \\
\hline Ferulic acid & 0.0564 & 1.6682 & Up-regulated \\
\hline 4-Hydroxy-3-methoxycinnamaldehyde & 0.0019 & 10.5479 & Up-regulated \\
\hline Cinnamic acid & 0.0036 & 2.5194 & Up-regulated \\
\hline \multicolumn{4}{|l|}{ GL20/CKO } \\
\hline p-Coumaric acid & 0.0407 & 0.1107 & Down-regulated \\
\hline p-Coumaraldehyde & NA & NA & \\
\hline Sinapic acid & NA & NA & \\
\hline Caffeate & 0.0369 & 1.156 & \\
\hline Sinapyl alcohol & NA & NA & \\
\hline p-Coumaryl alcohol & NA & NA & \\
\hline Caffeyl alcohol & NA & NA & \\
\hline Caffeyl aldehyde & NA & NA & \\
\hline Sinapinal dehyde & 0.0147 & 7.2121 & Up-regulated \\
\hline L-Phenylalanine & 0.0497 & 1.6486 & Up-regulated \\
\hline Coniferyl alcohol & 0.01762 & 19.5263 & Up-regulated \\
\hline Ferulic acid & 0.0113 & 2.3898 & Up-regulated \\
\hline
\end{tabular}




\begin{tabular}{|c|c|c|c|}
\hline 4-Hydroxy-3-methoxycinnamaldehyde & 0.0415 & 16.7289 & Up-regulated \\
\hline Cinnamic acid & 0.02470 & 2.1252 & Up-regulated \\
\hline \multicolumn{4}{|l|}{ GL60/CKO } \\
\hline p-Coumaric acid & 0.04766 & 0.079 & Down-regulated \\
\hline p-Coumaraldehyde & NA & NA & \\
\hline Sinapic acid & NA & NA & \\
\hline Caffeate & 0.0325 & 0.899 & \\
\hline Sinapyl alcohol & NA & NA & \\
\hline p-Coumaryl alcohol & NA & NA & \\
\hline Caffeyl alcohol & NA & NA & \\
\hline Caffeyl aldehyde & NA & NA & \\
\hline Sinapinal dehyde & 0.0057 & 5.2929 & Up-regulated \\
\hline L-Phenylalanine & 0.0073 & 1.5573 & Up-regulated \\
\hline Coniferyl alcohol & 0.0072 & 20.4520 & Up-regulated \\
\hline Ferulic acid & 0.03586 & 1.9201 & Up-regulated \\
\hline 4-Hydroxy-3-methoxycinnamaldehyde & 0.0001 & 17.3515 & Up-regulated \\
\hline Cinnamic acid & 0.0004 & 2.4017 & Up-regulated \\
\hline \multicolumn{4}{|l|}{ GL60/GL20 } \\
\hline p-Coumaric acid & 0.0386 & 0.7140 & Down-regulated \\
\hline p-Coumaraldehyde & NA & NA & \\
\hline Sinapic acid & NA & NA & \\
\hline Caffeate & 0.0339 & 0.7823 & Down-regulated \\
\hline Sinapyl alcohol & NA & NA & \\
\hline p-Coumaryl alcohol & NA & NA & \\
\hline Caffeyl alcohol & NA & NA & \\
\hline Caffeyl aldehyde & NA & NA & \\
\hline Sinapinal dehyde & 0.0157 & 0.7338 & Down-regulated \\
\hline L-Phenylalanine & 0.0014 & - & \\
\hline Coniferyl alcohol & 0.0082 & - & \\
\hline
\end{tabular}




\begin{tabular}{|lcl|} 
Ferulic acid & 0.0254 & 0.7034 \\
\hline 4-Hydroxy-3-methoxycinnamaldehyde & 0.0497 & -- \\
\hline Cinnamic acid & 0.0145 & -- \\
\hline NA: The metabolite was not checked; "-_-_-_": No difference was found between two libraries.
\end{tabular}

\section{Expression of genes related to monomer and polymer lignin contents}

All the genes related to monomer and polymer lignin contents were selected from the libraries to further analyze their expression after sucrose and IAA treatment. The data of these libraries has been published in previous study [20,32](Cheng et al. 2008, Cheng et al. 2020a). A total of eight genes related to monomer lignin was identified, and while expression of these genes did not change in the $\mathrm{CK} 1 / \mathrm{CO}$, GL20/C0, and GL50/C0 libraries after sucrose treatment (Fig. 4a), which indicated that sucrose had no effect on the content of monomer lignin at the transcription level. Genes involved in polymer lignin synthesis were also identified with these concentration of sucrose treatment. In fact, five genes were identified to be expressed at the transcriptional level. The mRNA levels of four genes, including NnLAC4, $N n L A C 7, N n L A C 11$, and NnLAC17 were increased, and one gene (NnLAC1), were decreased after $20 \mathrm{~g} / \mathrm{L}$ and $50 \mathrm{~g} / \mathrm{L}$ sucrose treatment (Fig. 4b). For these altered genes including $N n L A C 4, N n L A C 7, N n L A C 11$, no different change in expression was found between the CK1/CKO libraries, GL20/C0 libraries, and GL50/C0 libraries. However NnLAC17 was observed to have lower transcriptional level in GL20/C0 libraries than that of CK1/CKO and GL50/CO libraries (Fig. 4b), which indicated that $20 \mathrm{~g} / \mathrm{L}$ sucrose decreased NnLAC17 expression which was involved in polymer lignin synthesis.

For treatments with $10 \mu \mathrm{M}$ and $50 \mu \mathrm{M} I \mathrm{IA}, C 4 H, C C R, C A D$, and $F 5 H$ related with monomer lignin synthesis altered their expression, and while $P A L$ and $C O M T$ had no significant changes in transcriptional level. $C C R$ and $C A D$ had increased expression in the $A 1 / C 0$ and $C 1 / C 0$ libraries compared to the $B 1 / C 0$ library, and $F 5 H$ had more transcriptional level in the $\mathrm{C} 1 / \mathrm{CO}$ libraries than in the A1/C0 libraries and $\mathrm{B} 1 / \mathrm{C} 0$ libraries (Fig. 4C). In addition, all the gene relevant to polymer lignin synthesis was chosen from these libraries. We found that the expression of two genes (NnLAC4 and NnLAC17) involved in polymer lignin synthesis was identified, and NnLAC17 was found to have increased transcription level in the $\mathrm{C} 1 / \mathrm{CO}$ libraries compared to the A1/CO libraries and B1/CO libraries (Fig. 4d).

\section{Cloning and expression of NnLAC17}

NnLAC17 was cloned from the lotus and sequenced by Sangon Biotech (Shanghai) Co., Ltd. This gene had a full-length sequence of $1,749 \mathrm{bp}$ and encoded 583 amino acid residues. The deduced protein of this gene showed $84 \%, 84 \%, 83 \%$, and $85 \%$ similarity with that of Vitis riparia (XP_034687366.1), Vitis vinifera (XP_002284473.1), Spatholobus suberectus (TKY66042.1), and Trema orientale (PON84167.1), respectively (additional Fig. 1). In addition, a phylogenetic analysis of $L A C 17 s$ revealed that all $L A C 17 s$ 
were classified into seven groups, and most of these groups contained several sub-groups. SiLAC17, CsLAC17, NnLAC17, PeLAC17, PtLAC17, PdLAC17 and RCLAC17 were classified into a group, among which, CSLAC17 and NnLAC17 were classified into one sub-group, which indicated that $L A C 17$ from lotus was closely related to that of cucumber in gene sequence (Fig. $5 \mathrm{a}$ ).

Different concentrations of IAA and sucrose were applied to lotus seedlings, and NnLAC17 expression was analyzed after 2 days of treatment. No significant difference in NnLAC17 was observed at the transcription level in control plants and plants treated with $20 \mathrm{~g} / \mathrm{L}$ sucrose. However, $50 \mathrm{~g} / \mathrm{L}$ sucrose was found to remarkably enhance $N n L A C 17$ gene expression (Fig. 5b). A similar change was observed in seedlings treated with IAA. The seedlings treated with $150 \mu \mathrm{g} / \mathrm{L}$ IAA had higher mRNA levels than the control plants and those treated with $10 \mu \mathrm{g} / \mathrm{L}$ IAA (Fig. 5c). Based on an analysis of the gene expression in different organs, a higher expression of $N n L A C 17$ was observed in roots than in stems and leaves (Fig. $5 d)$.

\section{Functional analysis of NnLAC17 in transgenic Arabidopsis thaliana}

sn1301: NnLAC17 was constructed and overexpressed in Arabidopsis plants under the control of a cauliflower mosaic virus $35 \mathrm{~S}$ promoter to assess gene function. The "positive" plants were identified by hygromycin screen and the RT-PCR technique (Additional Fig. 2). The T2 generation of transgenic plants was planted in the base material, and root length and number were assessed with seedlings at 5-6 leaf age. Plant growth and the length of roots in transgenic plants and non-transgenic plants had no significant difference, while the number of roots in transgenic plants was greater than that in nontransgenic plants (Fig. 6a,b). Average twenty-six roots in each plant was observed in none transgenic plants at 5-6 leaf age, and approximately twenty roots were found in transgenic plants (Fig. 6c). Further analysis revealed that the content of polymer lignin was markedly increased in transgenic Arabidopsis plants after the overexpression of NnLAC17 (Fig. 6d). Compared with non-transgenic plants, NnLAC17 was found to regulate root formation by enhancing lignin content. Therefore, NnLAC17 regulated by sucrose signaling in the lotus is involved in AR development.

\section{Discussion}

The ARs of lotus play an important role in water and nutrition uptake in the lotus. In this experiment, we observed that a high concentration ( $50 \mathrm{~g} / \mathrm{L}$ ) of sucrose inhibited AR formation while a low concentration $(20 \mathrm{~g} / \mathrm{L})$ of sucrose promoted AR development (Fig. 1). The developmental process of AR, including the induction stage, which is the initial formation; the developmental stage of root primordium; and the expressed stage are found in lotus seedlings $[6,34]$. These stages are regulated by multiple factors, including light, plant hormones, mechanical damage, and sucrose $[20,32,35,36]$. IAA is involved in the early stages of root formation, and any incidence relevant to IAA synthesis and flux could affect root development [37, 38, 39]. Cheng et al. [32] reported that the exogenous application of low concentrations of IAA $(10 \mu \mathrm{M})$ increased the AR number. Through further analysis, these researchers revealed an IAA 
regulating role at the induction stage and developmental stages in lotus [20]. Another important regulator of AR development is sucrose, which has already been found in the plant kingdom [20]. The effect of sucrose, which is similar to that of hormones, occurs throughout the entire stage of AR development [36]. An interaction has been found to occur between sucrose and auxin in AR formation [20], which suggests that sucrose and auxin might simultaneously regulate AR development in lotus. To date, how sucrose and auxin regulate AR formation has not been revealed.

In this study, a microstructural observation of the development of AR was carried out. Treatment with 50 $\mathrm{g} / \mathrm{L}$ sucrose resulted in deeper crystal violet staining in AR primordium than that observed at CKO and after treatment with $20 \mathrm{~g} / \mathrm{L}$ sucrose (Fig. 2). Such findings suggest that a high correlation may exist between AR formation and lignin deposition. This phenomenon has also been identified in carrot taproots. Lignin accumulation is decreased after the application of exogenous IBA, which results in an increase in root length [40]. Lignin metabolism originates from the phenylpropanoid pathway and participates in various biological processes during plant growth [41, 42]. Lignin depletion causes plant dwarfism, which is caused by the disruption of cell wall formation [43]. Silencing of $\mathrm{C} 4 \mathrm{H}$ can markedly decrease lignin content and directly result in seedling lethality and an obstacle to leaf development [44]. Lignin deposition is found during root development in sweet potato, suggesting that lignin metabolism is closely correlated with root formation [45]. Further experiments shows that the decreased expression of $\mathrm{CH} 4$ reduces the number of Arabidopsis lateral roots relative to AUX transport [46]. Lotus seedlings treated with $50 \mathrm{~g} / \mathrm{L}$ sucrose were found to have a higher lignin content than at CKO. In addition, there was a significant decrease in lignin content following treatment with $20 \mathrm{~g} / \mathrm{L}$ sucrose (Fig. 3), suggesting that sucrose affected AR formation derived from the regulation of lignin metabolism. Lignin deposition is related to the age of the plant. Durkovic et al. [47] reported that 3-year-old plants have higher concentrations of lignin than 1-year-old plants. Further, callus cells in roots have higher lignin content than meristem [48]. In summary, root development and lignin deposition have a negative correlation, and lignin accumulation negatively affects root development.

Lignin synthesis includes two steps: monomer lignin synthesis and polymer lignin synthesis, and many genes are involved in these processes $[49,50]$. These biological processes are affected by many factors, including plant hormones, light, stress, temperature, and nitrate [51, 52, 53,54]. For the synthesis of monomer lignin, $P A L, C 4 H, 4 C L, C C R, C A D, S A D, C O M T$, and $F 5 H$ catalyze the conversion of phenylalanine into p-coumaryl alcohol, sinapyl alcohol, and coniferyl alcohol, resulting in the formation of monomer lignin with the help of POD $[24,49,55,56,57,58,59]$. The decreased expression of PALs and $4 C L$ reduces lignin accumulation $[24,60]$, and the increased expression of $P O D$ can significantly improve lignin content in plants [61]. In this study, we found no difference in the expression of $P A L, C 4 H, 4 C L, C C R, C A D, S A D$, $C O M T$, and $F 5 H$ under various concentrations of sucrose (Fig. 4). However, the contents of p-coumaric acid, caffeate, sinapinal aldehyde, and ferulic acid were markedly decreased in the GL50/GL20 libraries (Table 1), which indicated that more lignin was used in the synthesis of polymer lignin after $50 \mathrm{mg} / \mathrm{L}$ sucrose treatment. A further analysis was carried out in libraries treated with different concentrations of sucrose and IAA, and all NnLACs were selected to monitor the changes in gene expression related to lignin synthesis. We found that only NnLAC17 showed the same expression tendency; thus, the 
involvement of $N n L A C 17$ in polymer lignin synthesis might be the main factor resulting in different lignin contents in lotus seedlings responding to various concentrations of sucrose and IAA.

LACs play an important role in the polymerization of lignin, which is involved in

cell wall formation. In addition, the polymer distribution of lignin is regulated by LACs in gymnosperm compression wood [62]. Recently, LACs have been found to be involved in various abiotic stress responses in plants [53]. The overexpression of $\angle A C 2 P$ can improve water transport, which leads to enhanced plant drought adaptation [63]. $\mathrm{H}_{2} \mathrm{O}_{2}$ is reported to be an important signaling molecule. In fact, the exogenous application of $\mathrm{H}_{2} \mathrm{O}_{2}$ promotes AR formation in mung bean seedlings, and while the expression of Laccase7, which is related to lignin synthesis, was found to be significantly reduced [64], suggesting that the formation of AR and lignin content are opposing processes. Our data further revealed that increased lignin affected root development (i.e., a decrease in root number in transgenic plants) in transgenic plants of Arabidopsis thaliana after the overexpression of a lotus gene, NnLAC17 (Fig. 6). Such finding also indicated that LAC17 might be an important gene involved in lignin content, which regulated $A R$ formation in lotus.

\section{Conclusion}

Based on the monomer and polymer lignin content, microstructural observation, and metabolite product analysis of the lignin metabolism pathway, a higher concentration of sucrose promotes lignin content than a lower sucrose concentration in lotus seedlings. Genes involved in monomer and polymer lignin were analyzed. However, no difference in expression profile was found in the libraries following treatment with different concentrations of sucrose. As a result, the difference in monomer lignin was found to be derived from the efficiency of polymer lignin synthesis. Only NnLAC17, which is related to polymer lignin synthesis, was found to display different expression levels when exposed to different concentrations of sucrose and IAA. NnLAC17 had markedly enhanced expression in seedlings treated with $50 \mathrm{~g} / \mathrm{L}$ sucrose and $150 \mu \mathrm{M} \mathrm{IAA}$. Further, its overexpression markedly reduced root number. Therefore, we believed that lignin synthesis affect AR formation, and $N n L A C 17$ might be an important factor in the regulation of $A R$ formation in lotus seedlings.

\section{Declarations}

\section{Acknowledgements}

We extend our thanks to members of the BIG for their cooperation in obtaining the data during the AR formation of the lotus by RNA-seq technique. The authors also thank Editage for their editorial assistance. This work was supported by cooperation project of Yangzhou and Yangzhou University (YZ2020187), and the modern agricultural development project of Jiangsu Province (2020-SJ-003YD17). All the funders list in this manuscript have no role in the design and performance of all experiments, analysis of data, and in the writing of the manuscript. 


\section{Conflicts of interest/Competing interests.}

The authors declare that they have no competing interests.

\section{Ethics approval and consent to participate}

Not applicable.

\section{Consent to participate}

Not applicable.

\section{Consent for publication}

Not applicable.

\section{Availability of data and materials}

The materials of all the experiment was supported by aquatic vegetable Lab of Yangzhou University. The collection of seed complied with local and national guidelines and permissions of seed were obtained. The detail data derived from sucrose treatment has been deposited in NCBI database (Bioproject number). All the raw tags derived from IAA treatment were deposited in the National Center for Biotechnology Information (BioProject ID: PRJNA398315; accession number: SRR5944803SRR5944814)

\section{References}

1. Shen-Miller, J. (2002). Sacred lotus, the long-living fruits of China Antique. Seed Sci Res. 12, 131143.

2. Ming, R., VanBuren, R., Liu, Y., Yang, M., Han, Y., Li, L., et al. (2013). Genome of the Long living sacred lotus (Nelumbo nucifera Gaertn.). Genome Biol. 14: R41.

3. Cheng, L., Liu, H., Jiang, R., and Li, S. (2018). A Proteomics analysis of adventitious root formation after leaf removal in lotus (Nelumbo nucifera Gaertn.). ZNC. 73, 375-389.

4. Kevers, C., Hausman, J. F., Faivre-Rampant, O., Evers, D., and Gaspar, T. (1997). Hormonal control of adventitious rooting: progress and questions. J. Appl. Bot. Angew. Bot. 71, 71-79.

5. Li, S., Xue, L., Xu, S., Feng, H., and An L. (2009). Mediators, genes and signaling in adventitious rooting. Bot Rev. 75, 230-247. 
6. Rasmussen, A., Hosseini, S. A., Hajirezaei, M. R., Druege, U., and Geelen, D. (2015). Adventitious rooting declines with the vegetative to reproductive switch and involves a changed auxin homeostasis. J Exp Bot. 66, 1437-1452.

7. Teale, W. D., Paponov, I. A., and Palme, K. (2006). Auxin in action: signaling, transport and the control of plant growth and development. Nat Rev Mol Cell Biol. 7, 847-859.

8. Calvo-Polanco, M., Senorans, J., and Zwiazek, J. J. (2012). Role of adventitious roots in water relations of tamarack (Larix laricina) seedlings exposed to flood. BMC Plant Biol. 12: 99.

9. Rovere, D., Fattorini, L., Angeli, S. D., Veloccia, A., Falasca, G., and Altamura, M. M. (2013). Auxin and cytokinin control formation of the quiescent centre in the adventitious root apex of Arabidopsis. Ann Bot. 112, 1395-1407.

10. Fukaki, H., and Tasaka, M. (2009). Hormone interactions during lateral root formation. Plant Mol Biol. $69,437-449$.

11. Mergemann, H., and Sauter, M. (2000). Ethylene induces epidermal cell death at the site of adventitious root emergence in rice. Plant Physiol. 124, 609-614.

12. Mensuali-Sodi, A., Panizza, M., and Tognoni, F. (1995). Endogenous ethylene requirement for adventitious root induction and growth in tomato cotyledons and lavandin microcuttings in vitro. Plant Growth Regul. 17, 205-212.

13. Pan, R., Wang, J., and Tian, X. (2002). Influence of ethylene on adventitious root formation in mung bean hypocotyl cuttings. J. Plant Growth Regul. 36, 135-139.

14. Steffens, B., Wang, J., and Sauter, M. (2006). Interactions between ethylene, gibberellin and abscisic acid regulate emergence and growth rate of adventitious roots in deepwater rice. Planta. 223, 604612.

15. Riov, J., and Yang, S. (1989). Ethylene and auxin-ethylene interaction in adventitious root formation in mung bean (Vigna radiata) cuttings. J Plant Growth Regul. 8, 131-141.

16. Negi, S., Sukumar, P., Liu, X., Cohen, J. D., and Muday, G. K. (2010). Genetic dissection of the role of ethylene in regulating auxin-dependent lateral and adventitious root formation in tomato. Plant J. 61, 3-15.

17. Visser, E., Cohen, J. D., Barendse, G., Blom, C., and Voesenek, L. (1996). An ethylene-mediated increase in sensitivity to auxin induces adventitious root formation in flooded rumex palustrissm. Plant Physiol. 112, 1687-1692.

18. Cano-Delgado, A. I., Metzlaff, K., and Bevan, M. W. (2000). The eli1 mutation reveals a link between cell expansion and secondary cell wall formation in Arabidopsis thaliana. Development. 127, 33953405.

19. Takahashi, F., Sato-Nara, K., Kobayashi, K., Suzuki, M., and Suzuki, H. (2003). Sugar-induced adventitious roots in Arabidopsis seedlings. J Plant Res. 116,83-91.

20. Cheng, L., Zhao, M., Hu, Z., Liu, H., and Li, S. (2020a). Comparative transcriptome analysis revealed the cooperative regulation of sucrose and IAA on adventitious root formation in lotus (Nelumbo nucifera Gaertn). BMC Genomics. 21: 653.

Page $18 / 27$ 
21. Barros, J., Serk, H., Granlund, I., and Pesquet, E. (2015). The cell biology of lignification in higher plants. Ann. Bot. 115, 1053-1074.

22. Shioya, T., Akiyama, T., Yokoyama, T., and Matsumot, Y. (2017). Formation rate of benzyl cation intermediate from p-Hydroxyphenyl, guaiacyl, or syringyl nucleus in acidolysis of lignin. $J$ Wood Chem Tech. 37, 2: 75-86.

23. Cho, H., Chang, C., Huang, L., Tsai, J., and Liu, Z. (2011). Indole-3-butyric acid suppresses the activity of peroxidase while inducing adventitious roots in Cinnamomum kanehirae. Botanical Study. 52, $153-160$.

24. Quiroga, M., Guerrero, C., Botella, M. A., Barcelo, A., Amaya, I., Medina, M. I., et al. (2000). A tomato peroxidase involved in the synthesis of lignin and suberin. Plant Physiol. 122, 1119-1128.

25. Chou, C. H., Huang, Y. C., and Liu, Z. (2010). Peroxidase genes differentially respond to auxin during the formation of adventitious roots in soybean hypocotyl. Plant Growth Regul. 60, 151-161.

26. Syros, T., Yupsanis, T., Zafiriadis, H., and Economou1, A. (2004). Activity and isoforms of peroxidases,lignin and anatomy,during adventitious rooting in cuttings of Ebenus cretica L. J. Plant Physiol. 161, 69-77.

27. Singh, V., Sergeeva, L., Ligterink, W., Aloni, R., Zemach, H., Doron-Faigenboim, A., et al. (2019). Gibberellin promotes sweetpotato root vascular lignification and reduces storage-root formation. Frontiers in Plant Science. 10: 1320.

28. Ponniah, S. K., Thimmapuram, J., Bhide, K., Kalavacharla, V., and Manoharan, M. (2017). Comparative analysis of the root transcription of cultivated sweetpotato (Ipomoea batatas [L.] Lam) and its wild ancestor (Ipomoea trifida [Kunth] G. Don). BMC Plant Biol. 17: 9.

29. Li, S., Shi, R., Leng, Y., and Zhou, Y. (2016). Transcriptomic analysis reveals the gene expression profile that specifically responds to IBA during adventitious rooting in mung bean seedlings. $B M C$ Genomics. 17: 43.

30. Piacentinia, D., Ronzana, M., Fattorinia, L., DellaRoverea, F., Massimib, L., Altamuraa, M. M., et al. (2020). Nitric oxide alleviates cadmium-but not arsenic-induced damages in rice roots. Plant Physiol Biochem. 151, 729-742.

31. Teng, R.M., Wang, Y.X., Li, H., Lin, S. J., Liu, H., Zhang, J. (2021) Effects of shading on lignin biosynthesis in the leaf of tea plant (Camellia sinensis (L.) O. Kuntze). Mol Genet Genomics. 296: 165-177.

32. Cheng, L., Jiang, R., Yang, J., Xu, X., Zeng, H., and Li, S. (2018). Transcriptome profiling reveals an IAA-regulated response to adventitious root formation in lotus seedling. Z. Naturforsch. 73, 229-240.

33. Clough, S. J., and Bent, A. F. (1998). Floral dip: a simplified method for Agrobacterium-mediated transformation of Arabidopsis thaliana. Plant J. 16, 735-743.

34. Cheng, L., Liu, H., Han, Y., and Li, S. (2019). Transcriptome analysis of miRNAs expression reveals novel insights into adventitious root formation in lotus (Nelumbo nucifera Gaertn.). Mol Biol Rep. 46, 2893-2905. 
35. Cheng, L., Han, Y., Liu, H., Jiang, R., and Li, S. (2019). Transcriptomic analysis reveals ethylene's regulation involved in adventitious roots formation in lotus (Nelumbo nucifera Gaertn.). Acta Physiol Plant. 41: 97.

36. Cheng, L., Han, Y., and Zhao, M. (2020b). Gene expression profiling reveals the effects of light on adventitious root formation in lotus seedlings (Nelumbo nucifera Gaertn.). BMC Genomics. 21: 707.

37. Hobbie and Estelle. (1995). The axr4 auxin-resistant mutants of Arabidopsis thaliana define a gene important for root gravitropism and lateral root initiation. Plant J. 7, 211-220.

38. Casimiro, I., Marchant, A., Bhalerao, R. P., Beeckman, T., Dhooge, S., Swarup, R., et al. (2001). Auxin transport promotes Arabidopsis lateral root nitiation. Plant Cell. 13, 843-852.

39. Marchant, A., Bhalerao, R., Casimiro, I., Eklöf, J., Casero, P. J., Bennett, M., et al. (2002). AUX1 promotes lateral root formation by facilitating indole-3-acetic acid distribution between sink and source tissues in the Arabidopsis seedling. Plant Cell. 14, 589-597.

40. Khadr, A., Wang, G., Wang, Y., Zhang, R., Wang, X., Xu, Z., et al. (2020). Effects of auxin (indole-3butyric acid) on growth characteristics, lignification, and expression profiles of genes involved in lignin biosynthesis in carrot taproot. PeerJ. 8: e10492.

41. Brunetti, C., Fini, A., Sebastiani, F., and Gori, A. (2018). Modulation of phytohormone signaling: A primary function of flavonoids in plant environment interactions. Frontiers in Plant Sciences. 9: 1042

42. Vanholme, R., De Meester, B., Ralph, J., and Boerjan, W. (2019). Lignin biosynthesis and its integration into metabolism. Cur Opin. Biotech. 56, 230-239.

43. Dolan, W. L., Dilkes, B. P., Stout, J. M., Bonawitz, N. D., and Chapple, C. (2017). Mediato omplex subunits MED2, MED5, MED16, and MED23 genetically interact in the regulation of phenylpropanoid biosynthesis. Plant Cell. 29, 3269-3285.

44. Schilmiller, A. L., Stout, J., Weng, J. K., Humphreys, J., Ruegger, M. O., and Chapple, C. (2009). Mutations in the cinnamate 4-hydroxylase gene impact metabolism, growth and development in Arabidopsis. Plant J. 60, 771-782.

45. Singh, V., Zemach, H., Shabtai, S., Aloni, R., Yang, J., Zhang, P., et al. (2021). Proximal and distal parts of sweetpotato adventitious roots display differences in root architecture, lignin, and starch metabolism and their developmental fates. Fron. Plant Sci. 11: 609923.

46. Houari, I. E., Beirs, C. V., Arents, H. E., Han, H. B., Chanoca, A., Opdenacker, D., et al. (2021). Seedling developmental defects upon blocking CINNAMATE-4-HYDROXYLASE are caused by perturbations in auxin transport. New Phytol. 230, 2275-2291.

47. Durkovic, J., Kanuchova, A., Kacık, F., Solar, R., and Lengyelova, A. (2011). Genotype- and agedependent patterns of lignin and cellulose in regenerants derived from 80-year-old trees of black mulberry (Morus nigra L.). Plant Cell Tiss Organ Cult. 108, 359-370.

48. Eliyahu, A., Duman, Z., Sherf, S., Genin, O., Cinnamon, Y., Abu-Abied, M., et al. (2020). Vegetative propagation of elite Eucalyptus clones as food source for honeybees (Apis mellifera); adventitious roots versus callus formation. Israel Journal of Plant Science. 67, 83-97. 
49. Wang, Y., Teng, R., Wang, W., Wang, Y., Shen, W., and Zhuang, J. (2019). Identification of genes revealed differential expression profiles and lignin accumulation during leaf and stem development in tea plant [Camellia sinensis (L.) O. Kuntze]. Protoplasma. 256, 359-370.

50. Liu, Q., Luo, L., and Zheng, L. (2018). Lignins: biosynthesis and biological functions in plants. Int. J. Mol. Sci. 19: 335.

51. Han, M., Yang, N., Wan, Q., Teng, R., Duan, A., Wang, Y., et al. (2021). Exogenous melatonin positively regulates lignin biosynthesis in Camellia sinensis. Int. J. Biol. Macromol. 179, 485-499.

52. Zhang, X., Lu, M., Ludlow, R. A., Ma, W., and An, H. (2021). Transcriptome analysis reveals candidate genes for dietary fiber metabolism in Rosa roxburghii fruit grown under different light intensities. Hort Environ. Biol. doi: 10.1007/s13580-021-00359-6.

53. Lu, C., Yang, T., Zhang, Y., Miao, X., Jin, C., and Xu, X. (2021). Genomewide analyses and expression patterns under abiotic stress of LAC gene family in pear (Pyrus bretschneideri). Plant Biotech Rep. doi: 10.1007/s11816-021-00675-4.

54. Shao, C., Qiu, C., Qian, Y., and Liu, G. (2020). Nitrate deficiency decreased photosynthesis and oxidation-reduction processes, but increased cellular, transport, lignin biosynthesis and flavonoid metabolism revealed by RNA-Seq in Oryza sativa leaves. PLOS ONE. 15: e0235975.

55. Wang, G., Huang, Y., Zhang, X., Xu, Z., Wang, F., and Xiong, A. (2016). Transcriptome-based identification of genes revealed differential expression profiles and lignin accumulation during root development in cultivated and wild carrots. Plant Cell Rep. 35, 1743-1755.

56. Ye, Z., Zhong, R., Morrison, W. H., and Himmelsbach, D, S. (2001). Caffeoyl coenzyme A Omethyltransferase and lignin biosynthesis. Phytochem. 57, 1177-1185.

57. Duan, A., Feng, K., Wang, G., Liu, J., Xu, Z., and Xiong, A. (2019). Elevated gibberellin enhances lignin accumulation in celery (Apium graveolens L.) leaves. Protoplasma. 256, 777-788.

58. Hoffmann, L., Maury, S., Martz, F., Geoffroy, P., and Legrand, M. (2003). Purification, cloning, and properties of an acyltransferase controlling shikimate and quinate ester intermediate in phenylpropanoid metabolism. J. Biol. Chem. 278, 95-103.

59. Huang, J., Gu, M., Lai, Z., Fan, B., Shi, K., Zhou, Y., et al. (2018). Functional analysis of the Arabidopsis PAL gene family in plant growth, development, and response to environmental stress. Plant Physiol. $153,1526-1538$.

60. Gui, J., Shen, J., and Li, L. (2011). Functional characterization of evolutionarily divergent 4coumarate: coenzyme a ligases in rice. Plant Physiol. 157, 574-586.

61. Kim, Y. H., Kim, C. Y., Song, W. K., Park, D. S., Kwon, S. Y., Lee, H. S., et al. (2008). Overexpression of sweetpotato swpa4 peroxidase results in increased hydrogen peroxide production and enhances stress tolerance in tobacco. Planta. 227, 867-881.

62. Hiraide, H., Tobimatsu, Y., Yoshinaga, A., Lam, P. Y., Kobayashi, M., Matsushita, Y., et al. (2021). Localised laccase activity modulates distribution of lignin polymers in gymnosperm compression wood. New Phytol. 230, 2186-2199. 
63. Niu, Z., Li, G., Hu, H., Lv, J., Zheng, Q., Liu, J., et al. (2021). A gene that underwent adaptive evolution, LAC2 (LACCASE), in Populus euphratica improves drought tolerance by improving water transport capacity. Hort Res. 8:88.

64. Li, S., Xue, L., Xu, S., Fent, H., and An, H. (2009). IBA-induced changes in antioxidant enzymes during adventitious rooting in mung bean seedlings: The role of H2O2. Environ. Exp Bot. 66, 442-450.

\section{Figures}

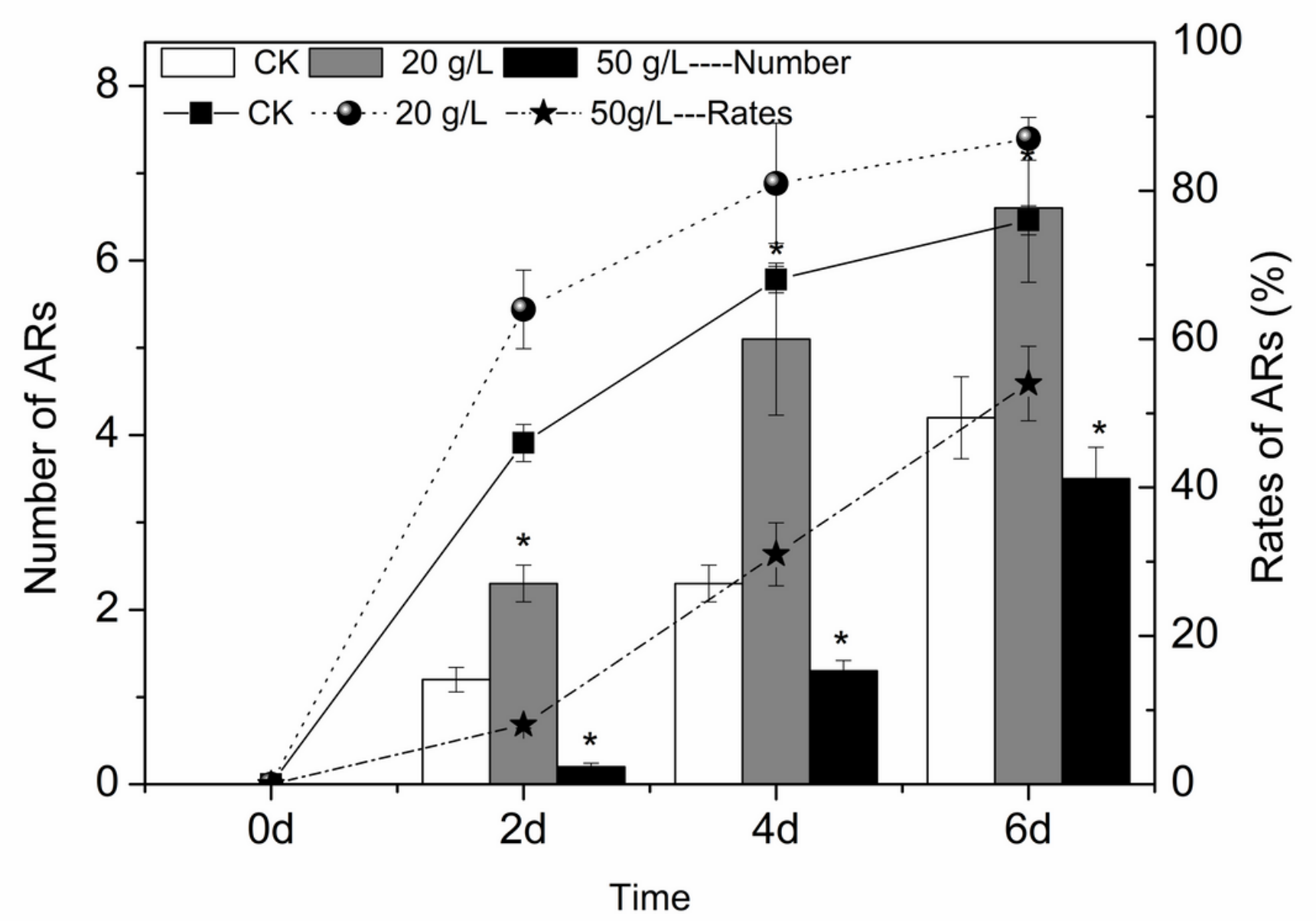

\section{Figure 1}

The influence of $20 \mathrm{~g} / \mathrm{L}$ and $50 \mathrm{~g} / \mathrm{L}$ sucrose on AR formation in lotus. Some data of this experiment had been published in Cheng et al. [20]. 

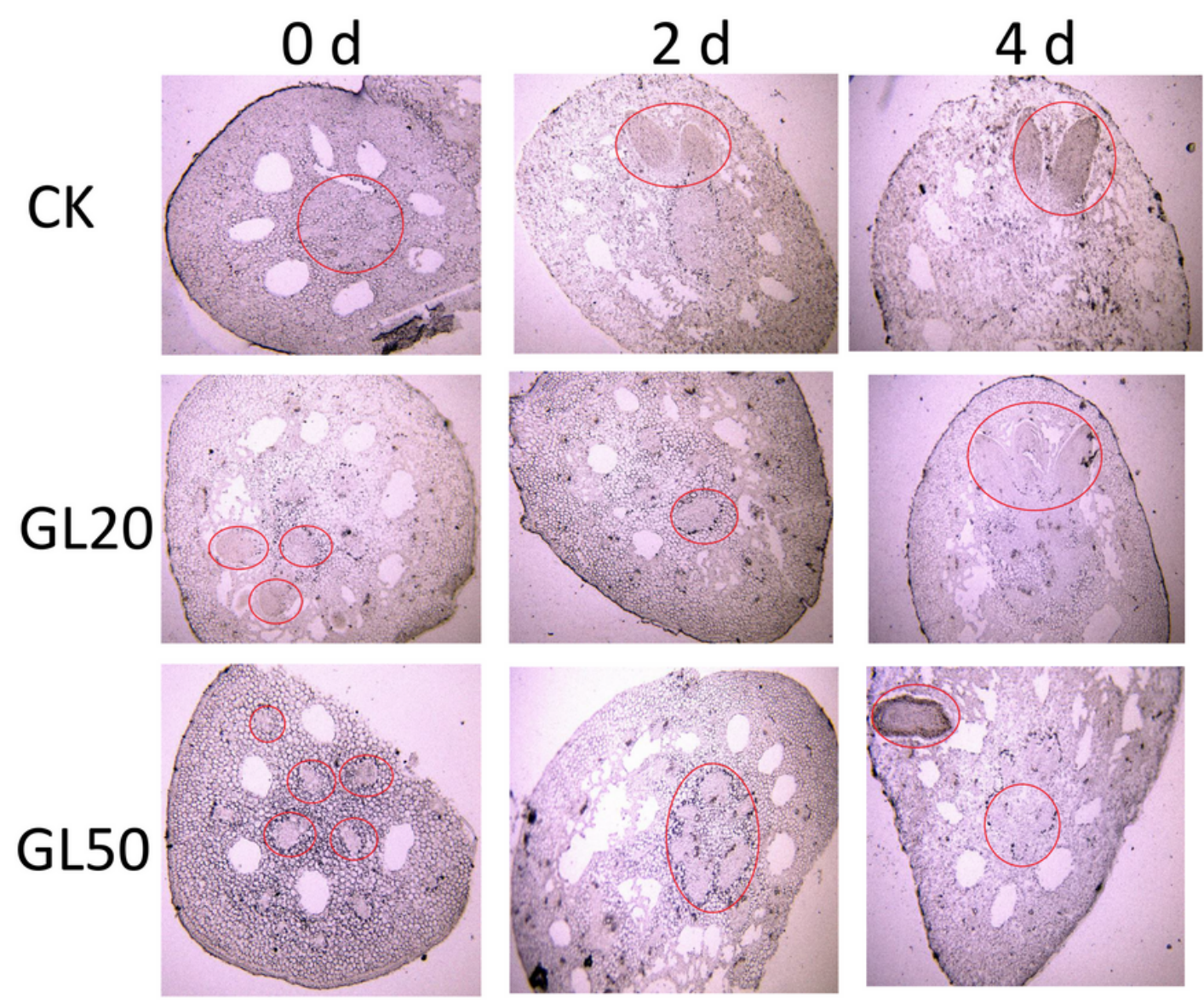
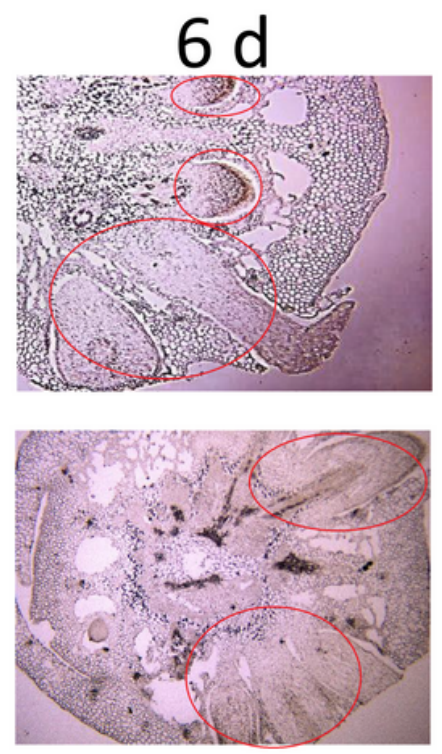

\section{Figure 2}

The change in lignin metabolism based on an observation of the microstructure during AR formation in lotus seedlings treated with $20 \mathrm{~g} / \mathrm{L}$ and $50 \mathrm{~g} / \mathrm{L}$ sucrose. 


\section{a}

+El EIC(269.1) Scan Lignin_com-400ug_ml.D

18.965

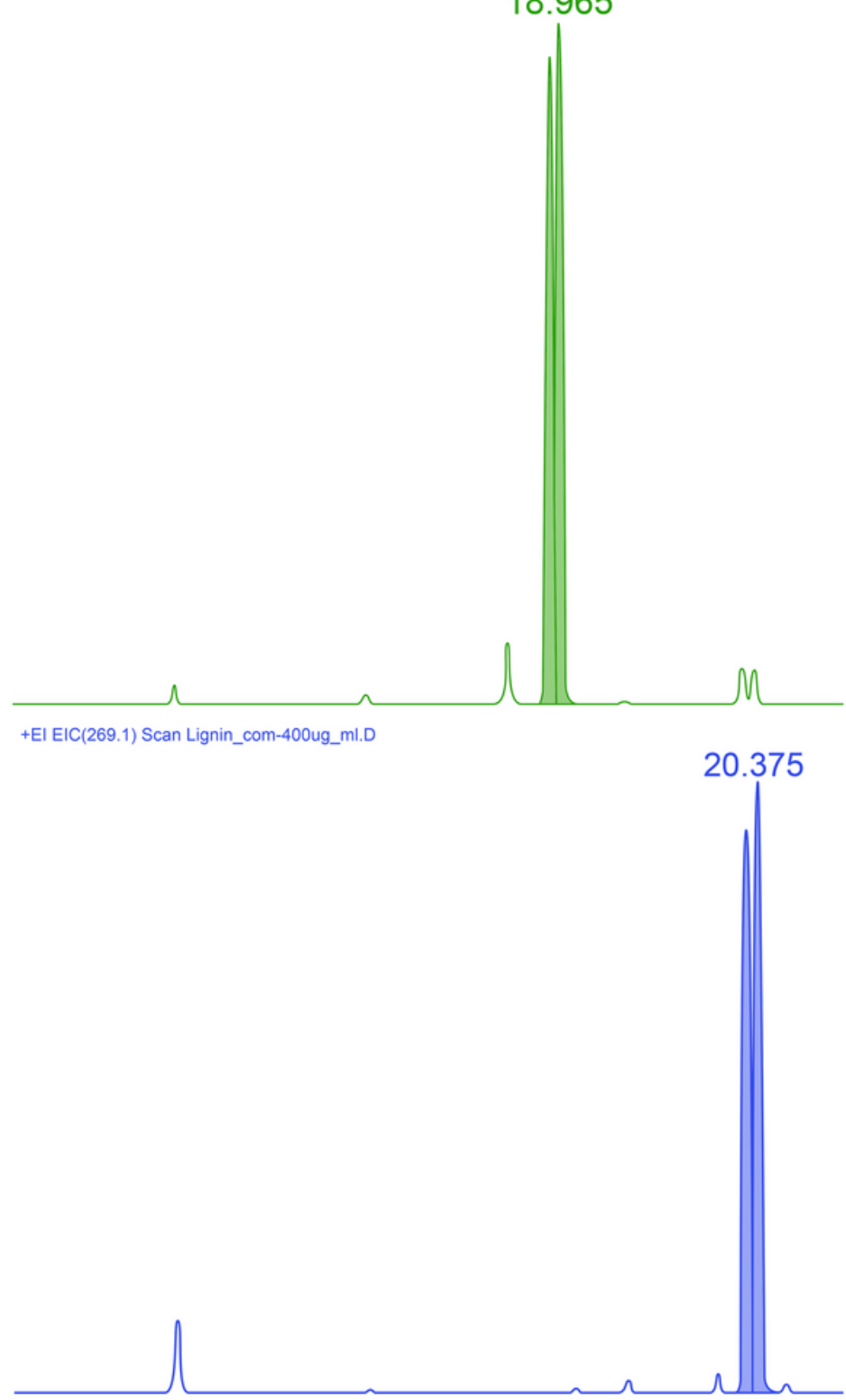

b

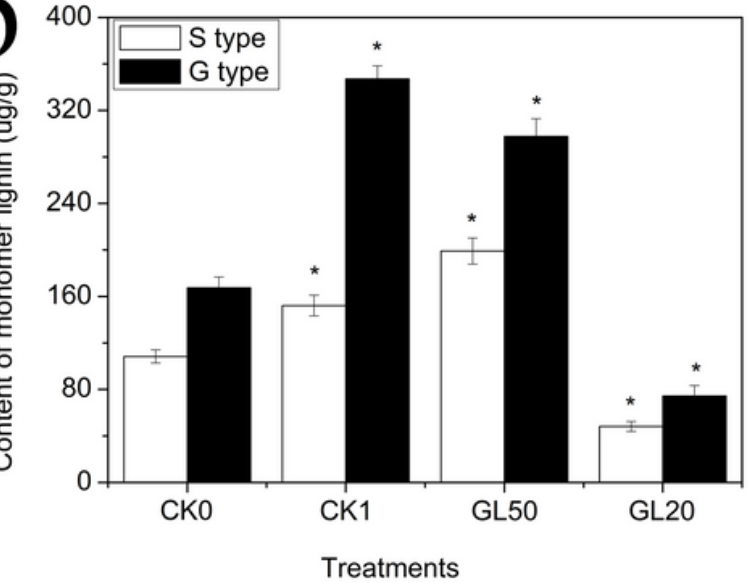

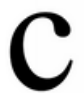

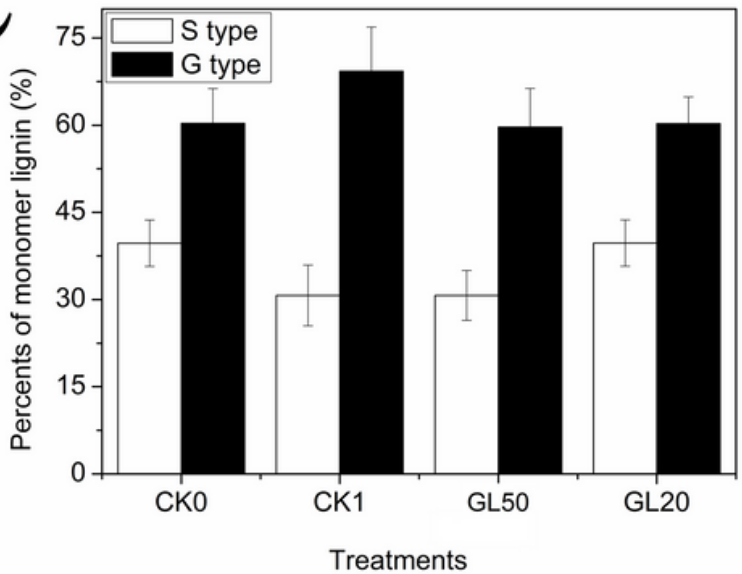

d

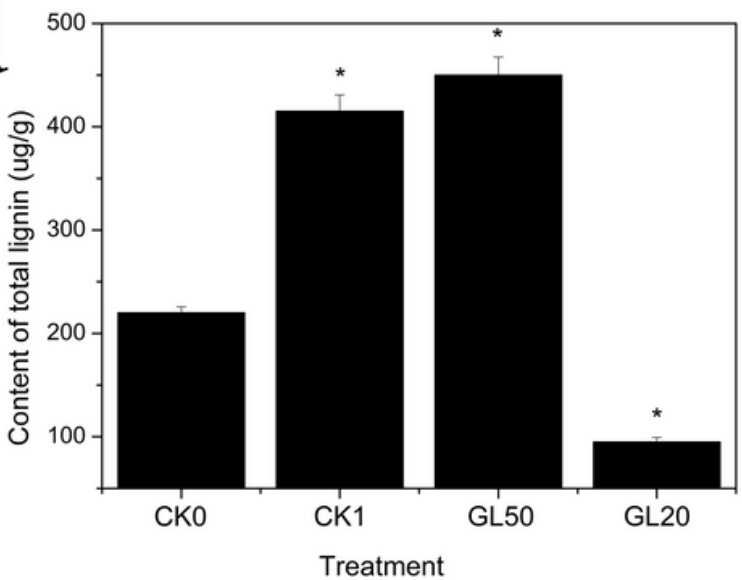

Figure 3

Identification of the AR lignin in lotus seedlings treated with $20 \mathrm{~g} / \mathrm{L}$ and $50 \mathrm{~g} / \mathrm{L}$ sucrose. a. The lignin was analyzed by ESI-QTRAP-MS/MS. b. Determination of the monomer lignin content in the C0, C1, GL50, and GL20 libraries. c. Determination of the monomer lignin types in the C0, C1, GL50, and GL20 libraries. d. Analysis of polymer lignin content in the C0, C1, GL50, and GL20 libraries. 

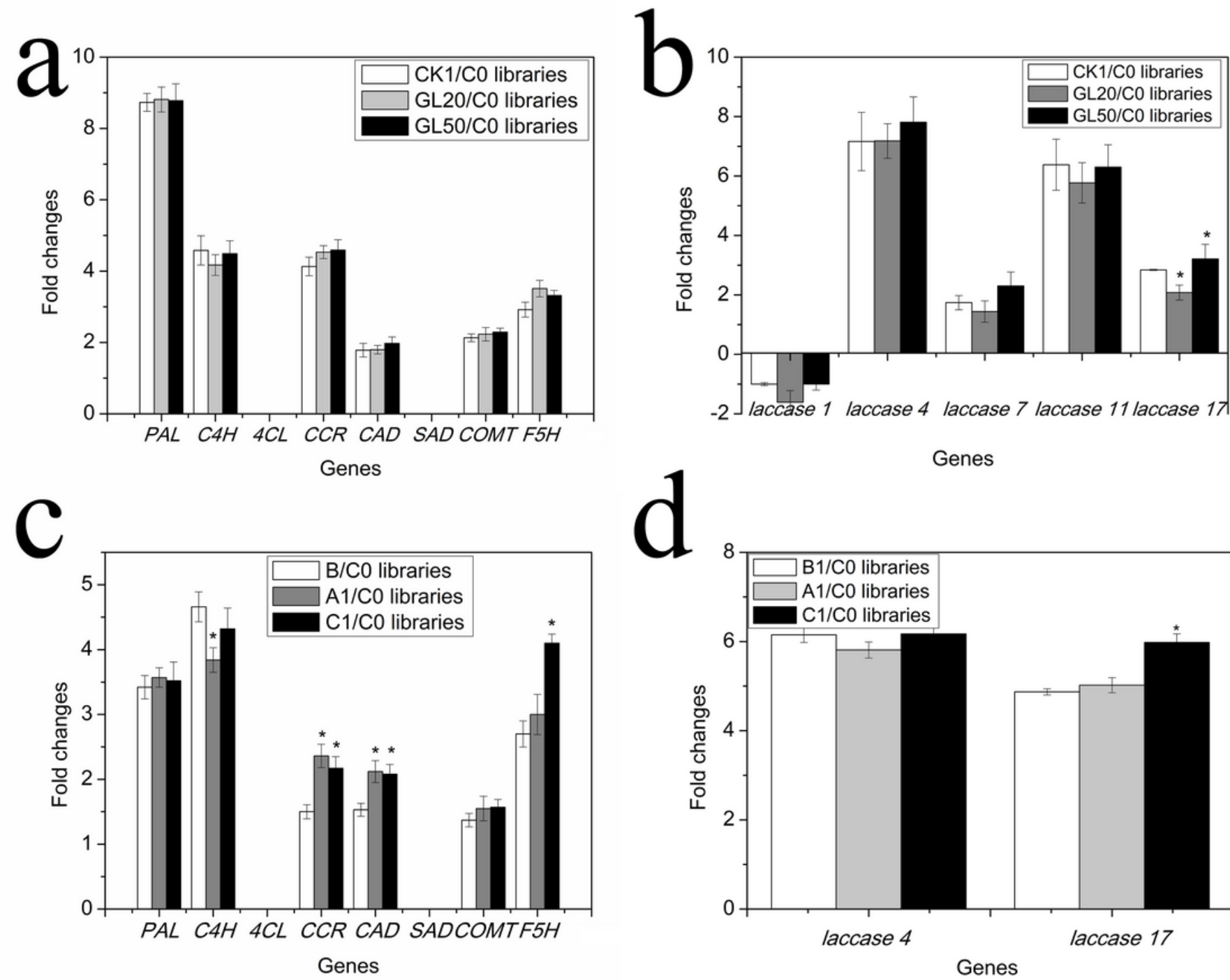

\section{Genes}

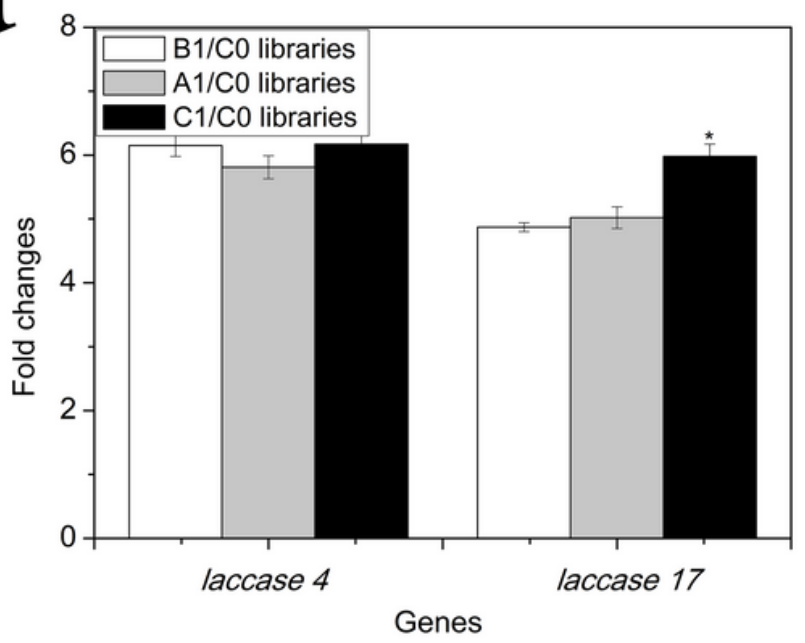

\section{Figure 4}

The expression of genes related to lignin synthesis during AR formation in lotus seedlings. a. The expression of genes related to monomer lignin synthesis in the GL20 and GL50 libraries. b. The expression of genes related to polymer lignin synthesis in the C0, C1, GL20, and GL50 libraries. c. The expression of genes related to monomer lignin synthesis in the $\mathrm{C} 0, \mathrm{~A} 1, \mathrm{~B}$, and $\mathrm{C} 1$ libraries. $d$. The expression of genes related to polymer lignin synthesis in the $\mathrm{C} 0, \mathrm{~A} 1, \mathrm{~B}$, and $\mathrm{C} 1$ libraries. 

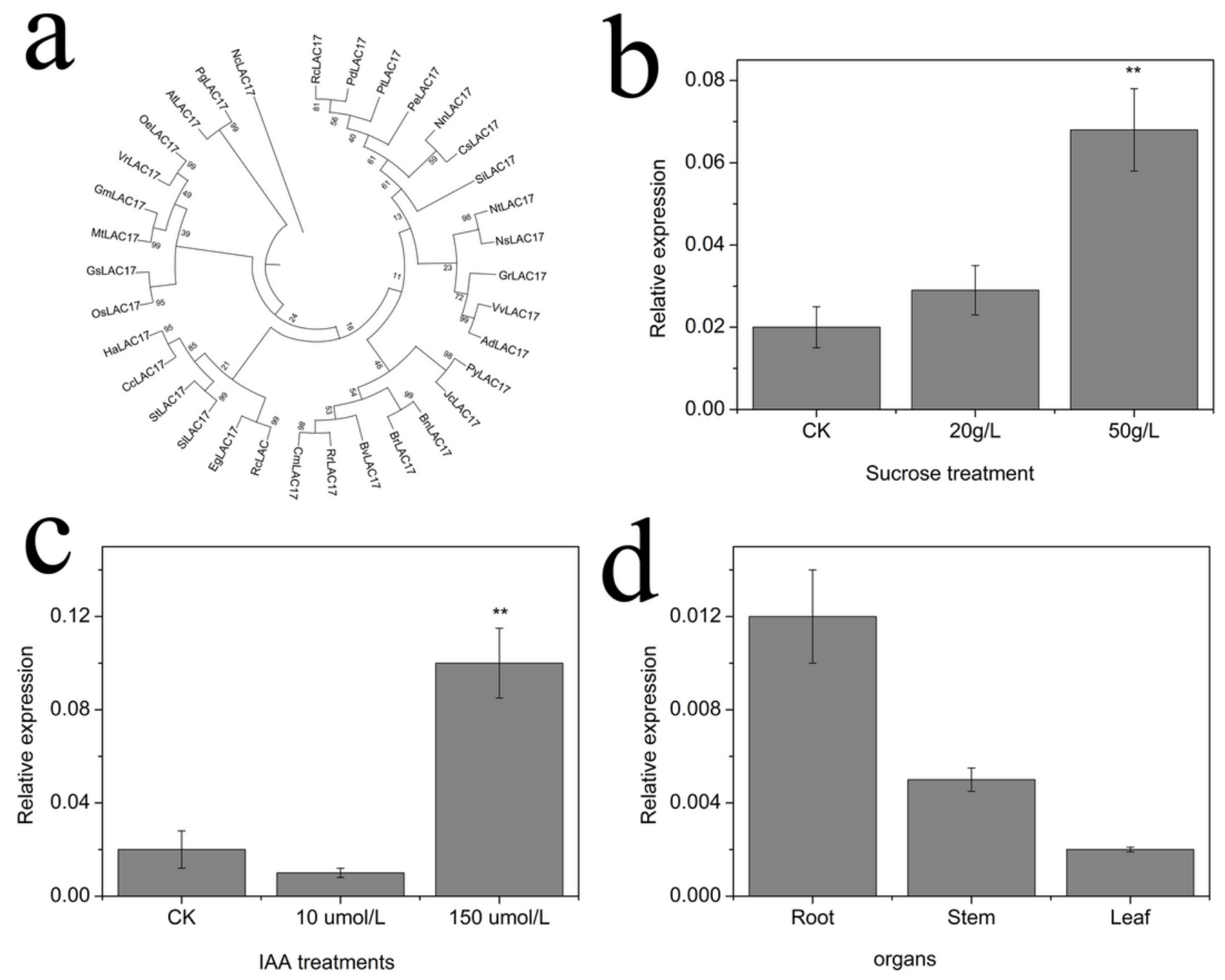

Figure 5

Cloning and expression analysis of NnLAC17 in lotus seedlings. a. Analysis of the similarity between $\mathrm{NnLAC17}$ of lotus with that of other different species. b. Relative expression of NnLAC17 in seedlings treated with $20 \mathrm{~g} / \mathrm{L}$ and $50 \mathrm{~g} / \mathrm{L}$ sucrose. c. Relative expression of NnLAC17 in seedlings treated with 10 $\mathrm{g} / \mathrm{L}$ and $150 \mathrm{~g} / \mathrm{L}$ IAA. d. Relative expression of NnLAC17 in different organs of lotus. 

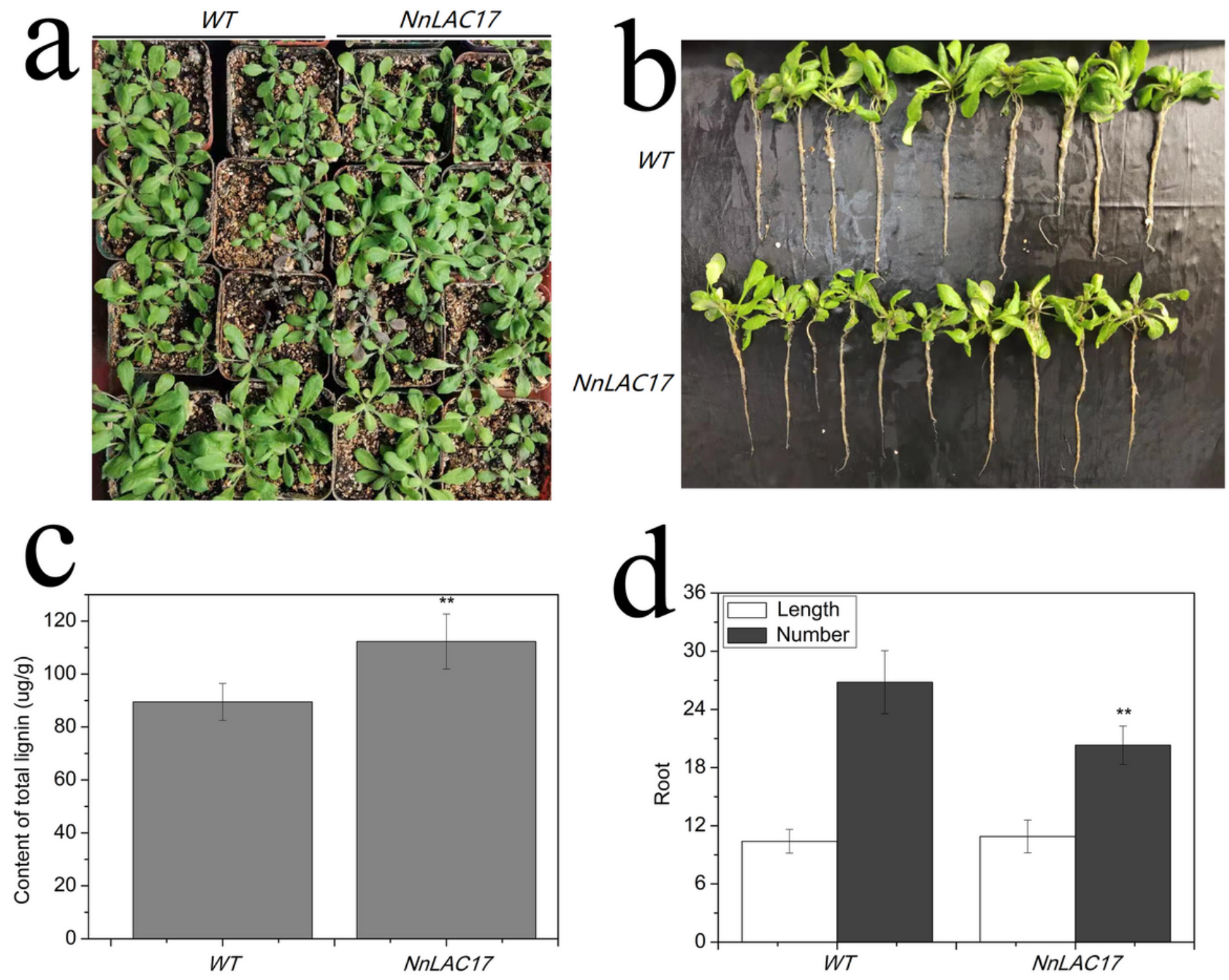

Figure 6

Functional analysis of NnLAC17 in transgenic Arabidopsis thaliana. a. Phenotypic investigation of NnLAC17 transgenic plants and wild-type plants at 6-7-leaf age. b. Comparative analysis of root length and number of transgenic plants and wild-type plants. c. Investigation of polymer lignin in NnLAC17 transgenic plants and wild-type plants. d. Determination of root length and number in NnLAC17 transgenic plants and wild-type plants.

\section{Supplementary Files}

This is a list of supplementary files associated with this preprint. Click to download.

- additionalfig.1.tif

- additionalfig.2.pptx.tif 